\title{
Microbiota Changes Due to Grape Seed Extract Diet Improved Intestinal Homeostasis and Decreased Fatness in Parental Broiler Hens
}

\author{
Jeremy Grandhaye ${ }^{1}\left(\mathbb{0}\right.$, Veronique Douard ${ }^{2}$, Ana Rodriguez-Mateos ${ }^{3}$, Yifan $\mathrm{Xu}^{3}{ }^{3}$, Alex Cheok ${ }^{3}$, \\ Antonella Riva ${ }^{4}{ }^{(\mathbb{D}}$, Rodrigo Guabiraba ${ }^{5}{ }^{(\mathbb{D}}$, Olivier Zemb ${ }^{6}{ }^{(\mathbb{D}}$, Catherine Philippe ${ }^{2}$, \\ Magali Monnoye ${ }^{2}$, Christophe Staub ${ }^{7}$, Eric Venturi ${ }^{7}$, Alix Barbe ${ }^{1}$, Christelle Ramé ${ }^{1}$, \\ Joelle Dupont ${ }^{1}$ and Pascal Froment ${ }^{1, *(1)}$ \\ 1 INRAE UMR85 Physiologie de la Reproduction et des Comportements, 37380 Nouzilly, France; \\ jeremy.grandhaye@inrae.fr (J.G.); alix.barbe@inrae.fr (A.B.); christelle.rame@inrae.fr (C.R.); \\ joelle.dupont@inrae.fr (J.D.) \\ 2 Micalis Institute, INRAE, AgroParisTech, Université Paris-Saclay, 78350 Jouy-en-Josas, France; \\ veronique.douard@inrae.fr (V.D.); catherine.philippe@inrae.fr (C.P.); magali.monnoye@inrae.fr (M.M.) \\ 3 Department of Nutritional Sciences, School of Life Course Sciences, Faculty of Life Sciences and Medicine, \\ King's College London, London SE1 7EH, UK; ana.rodriguez-mateos@kcl.ac.uk (A.R.-M.); \\ yifan.yu@kcl.ac.uk (Y.X.); alex.cheok@kcl.ac.uk (A.C.) \\ 4 INDENA, 38 Avenue Gustave Eiffel, 37095 Tours, France; antonella.riva@indena.com \\ 5 Infection and Innate Immunity in Monogastric Livestock, Centre INRAE Val de Loire, ISP UMR1282, \\ 37380 Nouzilly, France; rodrigo.guabiraba-brito@inrae.fr \\ 6 UMR 1388 GenPhySE, Université de Toulouse, INRAE, INPT, ENVT, 31320 Castanet Tolosan, France; \\ olivier.zemb@inrae.fr \\ 7 INRAE Unité Expérimentale de Physiologie Animale de l'Orfrasière UEPAO 1297, 37380 Nouzilly, France; \\ christophe.staub@inrae.fr (C.S.); eric.venturi@inrae.fr (E.V.) \\ * Correspondence: pascal.froment@inrae.fr; Tel.: +33-2-47-42-78-08
}

Received: 1 July 2020; Accepted: 27 July 2020; Published: 28 July 2020

\begin{abstract}
In poultry, the selection of broilers for growth performance has induced a deterioration in the health of the parental hens associated with poor reproductive efficiency. To improve these parameters, we administered to laying parental broiler hens a regular diet supplemented or not (Control) with a moderate $(1 \%)$ or a high level ( $2 \%$ ) of grape seed extract (GSE). The $1 \%$ GSE diet was administered from a young age (from 4 to 40 weeks of age) and the high level of $2 \%$ GSE was administered only during a 2-week period (from 38 to 40 weeks of age) in the laying period. The analysis of 40-week-old hens showed that 2\% GSE displayed a reduction in the fat tissue and an improvement in fertility with heavier and more resistant eggs. Seven monomer phenolic metabolites of GSE were significantly measured in the plasma of the $2 \%$ GSE hens. GSE supplementation increased the relative abundance of the following bacteria populations: Bifidobacteriaceae, Lactobacilliaceae and Lachnospiraceae. In conclusion, a supplementation period of only 2 weeks with $2 \%$ GSE is sufficient to improve the metabolic and laying parameters of breeder hens through a modification in the microbiota.
\end{abstract}

Keywords: broiler; grape seed; microbiota; adipose tissue

\section{Introduction}

Since the 1960s, commercial broilers have been selected for growth performance [1]. However, the parent stock of commercial broiler chickens have displayed a rapid alteration of their health status associated with elevated inflammation and fattening, joint problems and alteration of cardiac function and welfare. The consequences on broiler breeder hens are more pronounced than in males, 
since the hens are kept alive beyond 40 weeks. One of the features of the change in hen health status is the development of excess adiposity, which induces chronic inflammation and oxidative stress associated with the impairment of numerous cellular and tissue functions [2]. Moreover, genetic selection and ad libitum feeding cause excess of energy [3], leading to an aberrant follicular recruitment, dysregulation on pre-ovulatory follicle selection, inducing multiple ovulation, leading to poor reproductive efficiency $[4,5]$. To limit the alteration of metabolic and reproductive parameters during the laying period, the diet composition is adjusted to prevent excess adiposity [6] and to ameliorate laying rate and eggshell strength [7-12].

A change in dietary composition is frequently achieved through supplementation with antioxidants, among which selenium, vitamins and (poly)phenols are the most frequently used. Phenolic compounds are found in plant products (fruits, vegetables, flowers) and when metabolized by the organism they have been reported to have multiple biological effects in addition to their antioxidant properties [13,14]. Grape products such as grape juice, grape pomace or grape seeds are good sources of flavonoids and phenolic compounds; grape seed extracts (GSE) are of particular interest because they are easily usable in livestock diets. These compounds have potential health benefits such as reducing bone resorption or cardiovascular risk factors [15-17]. Recently, microbiota have been shown to play a role in the bioavailability of grape products, and gut bacteria may play a key role in mediating or potentiating their health effects [18-20]. Among the flavonoids present in GSE, the small intestine readily absorbs monomers such as catechins, but oligomers or polymers are not absorbed and reach the colon where they are metabolized by gut bacteria into phenolic acids and therefore absorbed by the colonic cells [21,22]. Some studies have reported the beneficial effects of grape product supplementation in broilers. Hence, chicks supplemented for 35 days with grape (grape extract, grape pomace, or GSE) showed reduced mortality rates and lesion scores after E. tenella infection [23]. Dietary supplementation with grape seed oil (21 days) also improved the quality of broiler chicken meat [24]. However, a high concentration of GSE supplementation ( $5 \mathrm{~g} / \mathrm{kg}$ for 21 days) can have deleterious effects by reducing feed conversion in broilers and consequently stunting growth [25]. However, to our knowledge, no data have focused on the effect of a GSE supplemented diet on female parental broiler hens during the reproductive period.

GSE can also modify the microbiota composition [26]. (Poly)phenols may change intestinal microbial composition by selectively inhibiting the growth of some pathogenic bacteria while enhancing the growth of probiotic bacteria [27]. In mice, a diet enriched in high-flavonoid apples increased the number of total bacteria by $6 \%$ [28] and the supplementation of a high fat diet with proanthocyanidin specifically decreased the relative abundance of Lactococcus and Bacteroides [29]. Several studies showed a positive link between gut microbiota modification in response to GSE and improvement of specific metabolic parameters such as adiposity and inflammation [29]. The role of the gut microbiota in regulating body composition and metabolic outcome in obese mice and humans has been well established [30,31]. However, little is known about the role of microbiota in growth performance and body composition in broilers. In hens, the modification of microbiota could also influence reproductive performance. Indeed, the use of a probiotic mixture of Bacillus subtilis and Enterococcus faecium increased the egg production rate, the egg weight, eggshell strength, and albumen height in laying hens [32].

The objective of the present study was to investigate in parental female broiler the effect of a GSE supplemented diet on performance and metabolic parameters linked to fatness. The caecal microbiota composition and its metabolic adaptation to the GSE was also analyzed in order to decipher its potential role in mediating the GSE effects. In order to optimize future dietary supplementation procedures, two different approaches were used: a long period of dietary supplementation during almost the entire life of the hens with a low amount of GSE and a short period of GSE exposure (2 weeks during the laying period). 


\section{Materials and Methods}

\subsection{Animals}

Thirty-six female parent broiler breeders (Cobb 500) from a commercial breeding unit of Hendrix Genetics (Saint Laurent de la Plaine, France) were studied until they were 40 weeks old. All experiments were approved by the Ethics Committee in Animal Experimentation of Val de Loire CEEA Vdl registered by the National Committee 'Comité National de Réflexion Ethique sur 1'Expérimentation Animale' under the number 19 (APAFIS\# 10237-201706151202940v3). All experiments were performed in accordance with the European Communities Council Directive 2010/63/UE.

The 36 parental hens were distributed in 3 homogeneous groups of 12 hens. Each group was divided into 2 pens of $3 \mathrm{~m}^{2}$ ( 6 hens/pen). The animals were reared in rooms initially bedded with $8 \mathrm{~cm}$ of clean shavings or hulls at the Experimental Unit of the Poultry Experimentation Center of Tours (UEPEAT, Nouzilly, France) according to the conventional conditions of breeding. Light conditions were $14 \mathrm{~h}$ of light per day (minimum light intensity of 20 lux) at their arrival followed by a gradual decrease to approximately $8 \mathrm{~h}$ at the 1 st week, kept constant until the age of photostimulation (21st week) and then a gradual increase until reaching $14 \mathrm{~h}$ of light per day at the end of study (40th week) every 4 weeks. Housing temperature began at $31^{\circ} \mathrm{C}$ and was decreased gradually to $21.5^{\circ} \mathrm{C}$, with a range of humidity between 35 and $70 \%$ during the 40 weeks. Ten hens per group were selected to measure the bodyweight, and the thickness of back fat by ultrasound.

The fat composition of the chickens was estimated by dorsal ultrasound (MyLab 30 Gold Vet ultrasound scanner, Hospimedi France, Saint-Crépin-Ibouvillers, France) equipped with 2 linear probes (Esaote L332 and L435) as described in [6]. Only the measurements at the 40th week of age are represented. At the 38th and 39th week of age, all eggs were collected and individually weighed (KERN Scale-ref. PCB 250-3, Kern and Sohn, Balingen, Germany). The analysis of laying rate (number of egg per hen per day) and egg weight were performed every day in all pens (36 hens in total). Eggs were recovered 2 times per day for 2 weeks and each egg was weighed; in total, at least 120 eggs per group were measured. Each day, the broken eggs were noted and were reported to daily egg production per group.

At 40 weeks, all hens were stunned by electrocution and killed by exsanguination as recommended by the ethical committee. The blood samples were collected in heparin tubes, centrifugated to keep the plasma $\left(1500 \mathrm{~g}, 10 \mathrm{~min}, 4^{\circ} \mathrm{C}\right)$, aliquoted and stored at $-20^{\circ} \mathrm{C}$ until analysis. The cecal digesta were weighted and stored at $-80^{\circ} \mathrm{C}$ until analysis. The cecum tissue (100 mg) was washed in the phosphate buffered saline (PBS), then stored at $-80^{\circ} \mathrm{C}$.

\subsection{Nutrition and Feeding Strategies}

From the first day to the 4th week, all birds received an ad libitum diet (free access to food). From the 4th week to the 40th week of age, chicks received three different diets according to Hendrix Genetics' recommendation: grower (from week 4 to 18), prebreeder (from week 18 to 21) and breeder diets (from week 21 to 40). At the 4th week, two groups of hens were separated in function of 2 types of diets: control diet and the same diet supplemented with GSE at 1\% of total diet. The GSE supplement was provided by INDENA (Tours, France) The composition of GSE was analyzed using high performance liquid chromatography (HPLC) by INDENA, and this showed that the most important component was the procyanidins (>90\%). At week 38 of age, a third group was created from the control group and received a diet supplemented with $2 \%$ of GSE for two weeks. In order to adjust the amount of feed consumed by animals, animals in the control pens were weighed and then feed was adjusted weekly with respect to the theoretical curve provided by the supplier. The resulting three groups were: control, $\mathrm{n}=12$; long time 1\% GSE supplemented diet from week 4 to 40 of age, $\mathrm{n}=12$; and a short time $2 \%$ GSE supplemented diet from week 38 to 40 of age, $\mathrm{n}=12$ (protocol in Supplemental Data 1). 


\subsection{Analysis of Plasma (Poly)Phenols by Ultra Performance Liquid Chromatography Coupled with Triple Quadrupole Mass Spectrometry (UPLC-Q- $q-Q M S$ )}

The chicken plasma samples were first hydrolyzed with $\beta$-glucuronidase/sulfatase from Helix pomatia (Type $1 \mathrm{H}$, Sigma-Aldrich, Saint Louis, MO, USA). The identification and quantification of (poly)phenol metabolites in plasma after GSE consumption was performed using micro-elution solid phase extraction ( $\mu$-SPE), as previously described [33,34], followed by UPLC-Q-q-Q MS. The detection of target metabolites was performed on a SHIMADZU Triple Quadrupole Mass Spectrometer (LCMS-8060, SHIMADZU, Kyoto, Japan) through an electro-spray ionization (ESI) source in negative mode. Extracted samples $(5 \mu \mathrm{L})$ were injected through a Raptor Biphenyl column $(2.1 \times 50 \mathrm{~mm}, 1.8 \mu \mathrm{m}$, Restek, Bellefonte, PA, USA) with a compatible Raptor Biphenyl Guard Cartridge $(5 \times 2.1 \mathrm{~mm}$, Restek, Bellefonte, PA, USA) in the UPLC system following a previously validated separation method [30]. Authentic standards were injected for the identification and quantification of individual (poly)phenols. Recoveries of the compounds during $\mu$-SPE were estimated with the isotopically labeled internal standard $( \pm)$ catechin-2,3,4-13 $\mathrm{C} 3$ (Sigma-Aldrich, Steinheim, Germany). Analysis of the plasma (poly)phenols were performed on 4 hens from (control) group, 5 hens from (1\% LT) group and 5 hens from ( $2 \% \mathrm{ST})$ group.

\subsection{Microbiota DNA Extraction and $16 S$ RNA Sequencing}

DNA from bacteria was extracted from caecum content (12 samples per group) using G'NOME DNA isolation kit (MP Biomedicals, Strasbourg, France) [35]. V3-V4 region of the 16S rRNA genes was amplified using MolTaq (Molzym, Plaisir, France), 50 ng DNA and the primers V3F: TACGGRAGGCAGCAG and V4R: ATCTTACCAGGGTATCTAATCCT [36]. Purified amplicons were sequenced using the MiSeq sequencing technology (Illumina) at the GeT-PLaGe platform (Toulouse, France). Paired-end reads obtained from MiSeq sequencing were analyzed using the Galaxy-supported pipeline named FROGS (Find, Rapidly, OTUs, Operational Taxonomic Units) with Galaxy Solution) [37]. For the preprocessing, reads with length $\geq 380 \mathrm{bp}$ were kept. The clustering and chimera removal tools followed the guidelines of FROGS [37]. Assignation was performed using SILVA132 16S pintail100. OTUs with abundances lower than $0.005 \%$ were removed from the analysis [38].

\subsection{Tissue RNA Extraction and Reverse Transcription Reaction}

Total RNA from caecal tissue was extracted by using the TRIzol ${ }^{\circledR}$ reagent (Invitrogen, by Life Technologies, Villebon sur Yvette, France). Total RNA $(1 \mu \mathrm{g})$ was reverse transcribed with $0.5 \mathrm{mM}$ of dNTP, $2 \mathrm{M}$ of RT-Buffer, $0.5 \mu \mathrm{g} / \mu \mathrm{L}$ of OligodT, $0.125 \mathrm{U}$ of ribonuclease inhibitor and 0.05U of RT-MMLV (Promega, France) for $1 \mathrm{~h}$ at $37^{\circ} \mathrm{C}$ (Thermocycler PE9700, Perkin Elmer, France). cDNA was stored at $-80^{\circ} \mathrm{C}$ until qPCR. Biological samples from 10 hens per group were analyzed

\subsection{Real Time PCR}

Real-time PCR was performed using the MyiQ Cycle Device (Bio-Rad, Marnes-la-Coquette, France), in a mixture with $9 \mu \mathrm{L}$ SYBR Green Supermix 1X Reagent (Bio-Rad, Marnes-la-Coquette, France), $0.23 \mu \mathrm{L}$ of specific primers ( $250 \mathrm{nM}$ ) as indicated in (Supplemental Data 2), $5.45 \mu \mathrm{L}$ of cDNA diluted 1:5 in water, and $5 \mu \mathrm{H} 2 \mathrm{O}$ for a total volume of $20 \mu \mathrm{L}$. The samples were set up in duplicate on the same plate according to the following procedure: after an incubation of $2 \mathrm{~min}$ at $50{ }^{\circ} \mathrm{C}$ and a denaturation step of $10 \mathrm{~min}$ at $95^{\circ} \mathrm{C}$, samples were subjected to $40 \mathrm{PCR}$ cycles $\left(30 \mathrm{~s}\right.$ at $95^{\circ} \mathrm{C}, 30 \mathrm{~s}$ at $60{ }^{\circ} \mathrm{C}, 30 \mathrm{~s}$ at $72{ }^{\circ} \mathrm{C}$ ), followed by the acquisition of the melting curve. Primers' efficiency (E) was performed from serial dilutions of a pool of obtained cDNA and ranged from 1.8 to 2 . as described in [12]. Three reference genes (GAPDH, EEF1A1 and ACTB) were used. For each gene, expression was calculated according to primer efficiency and quantification cycle $(\mathrm{Cq})$, where expression $=\mathrm{E}^{-\mathrm{Cq}}$. The relative expression of the gene of interest was analyzed to the relative expression of the geometric mean of the three reference genes. 


\subsection{Protein Extraction and Western Blotting}

Total protein was extracted from the caecum $(100 \mathrm{mg})$ in lysis buffer and exposed to 3 repeated freeze/thaw cycles. The protein concentration in the supernatants were determined using a colorimetric assay kit (DC assay kit; Uptima Interchim, Montluçon, France). The proteins extracted $(80 \mu \mathrm{g})$ were denatured, subjected to SDS-PAGE in a $12 \%$ polyacrylamide gel, transferred onto nitrocellulose membranes and incubated at $4{ }^{\circ} \mathrm{C}$ overnight with the following antibodies: P53 and IL6 produced by Agro-Bio (Agro-Bio, La Ferté Saint Aubin, France). The targeting peptides are EFIQETFDSEKQNVESLC from IL6 (gallus gallus, NCBI Reference Sequence: NP_989959.1) and peptide CEGNPQARYHDDETTKRK from P53 (gallus gallus, NCBI Reference Sequence: NP_990595.1). All antibodies were used at 1:1000 dilution in Western blotting. The signal was detected by enhanced chemiluminescence (Amersham Pharmacia Biotech, Orsay France) and the signals were quantified by using ImageJ software (NIH, Bethesda, MD, USA). The results are expressed as the intensity signal in arbitrary units, after normalization by an internal standard (tubulin, Sigma-Aldrich Saint-Louis, MO, USA). Analysis was performed on biological samples from 5 hens per group

\subsection{Oxidative Stress Analysis}

ROS-Glo ${ }^{\mathrm{TM}} \mathrm{H}_{2} \mathrm{O}_{2}$ Assay (Promega, Charbonnieres, France) was performed on plasma to analyze oxidative stress (10 biological samples/group). Assays were realized according to the manufacturer's instructions. Briefly, samples were stressed with $\mathrm{H}_{2} \mathrm{O}_{2}$ Substrate Solution for $3 \mathrm{~h}$, then, samples were incubated 20 min with ROS-Glo ${ }^{\mathrm{TM}}$ Detection Solution in the dark to stabilize the luminescent signal. The plate was measured using a microplate reader, Luminoskan Ascent (VWR International, France) to record luminescence.

\subsection{Metabolites}

Phospholipides, cholesterol, triglycerides, uric acid, calcium, and glucose were measured by using the following spectrophotometric assays, respectively (Biolabo, Maizy, France), and lactate concentration by a Sigma-Aldrich kit (Sigma-Aldrich Saint-Louis, MO, USA). ATP concentrations and caspase 3 activity were measured by using the CellTiter-Glo ${ }^{\mathrm{TM}}$ ATP Assay Kit and Caspase-Glo ${ }^{\mathrm{TM}}$ Assay (Promega, Charbonnieres, France), respectively, according to the manufacturer's instructions. Measurement were performed on biological samples from 10 hens per group.

\subsection{Hormones}

Concentration of adiponectin and chemerin in plasma were measured by ELISA (MyBioSource ADPN ELISA kit: Chicken Total Adiponectin ELISA Kit, MyBioSource Chicken CML ELISA Kit, San Diego, CA, USA) [39]. Measurement were performed on biological samples from 10 hens per group.

\subsection{Statistical Analysis}

One-way ANOVA test using GraphPad Prism 8 (La Jolla, CA, USA) was used to evaluate differences between groups. The results are expressed as mean \pm SEM. Values were determined to be significant when ${ }^{*} p<0.05,{ }^{* *} p<0.01,{ }^{* *} p<0.001$ or by different letters indicating significant difference between groups $(p<0.05)$.

$16 S$ sequencing data were analyzed using the Phyloseq [40], ggplot2 [41] R packages in additions to custom scripts. Samples were rarefied to even sampling depths before computing within-samples compositional diversities (observed richness and Inverse Simpson) and between-samples compositional diversity (Bray-Curtis and Jaccard dissimilarities). Principal coordinate analysis (PCoA) was performed on Bray-Curtis and Jaccard dissimilarities. Raw, unrarefied OTU counts were used to produce relative abundance graphs. Observed richness and inverse Alpha diversity data were analyzed using 1-way ANOVA. A permutational multivariate analysis of variance (PERMANOVA) test was performed on the Bray-Curtis and Jaccard matrices using 9999 random permutations and at a significance level of 
0.01. Phylum and family relative abundances were compared using a Kruskal-Wallis test followed by Dunn's test.

\section{Results}

\subsection{GSE Diet Influences Metabolism}

First, the addition of 2\% GSE for 2 weeks (short treatment, 2\% ST, from 38 to 40 weeks of age) in the diet decreased significantly $(p<0.05)$ the body weight of hens (Figure $1 \mathrm{~A})$ as well as the fatness measured by ultrasound compared to the control group (Figure 1B). The group that received 1\% GSE (long treatment, 1\% LT, from 4 to 40 weeks of age) did not show changes in body weight or fatness compared to control $(p>0.05)$. In order to clarify the mechanism underlying the decrease in adiposity and body weight in the hens of the $2 \%$ ST group, we focused on two hormones produced by adipose tissue. The adiponectin plasmatic levels were lower and chemerin plasmatic levels were higher in both GSE groups (Figure 1C,D, $p<0.001$ ) when compared to the control group. Then, the blood lipid profile was assessed (Table 1). The phospholipid levels decreased significantly $(p<0.05)$ in the plasma of both GSE groups when compared to the control group, while cholesterol and triglycerides levels remained unchanged $(p>0.05)$. The uric acid concentration was significantly $(p<0.01)$ reduced in both GSE groups when compared to the control group. Calcium concentration was significantly $(p<0.01)$ lower in the hens of the $2 \%$ GSE group when compared to the two other groups. After $8 \mathrm{~h}$ of starvation, lactate and glucose levels were similar in all groups. Importantly, the blood reactive oxygen species (ROS) levels were lower in hens of the $2 \%$ GSE group than in those of the control group, confirming the antioxidant properties of GSE $(p<0.05)$.
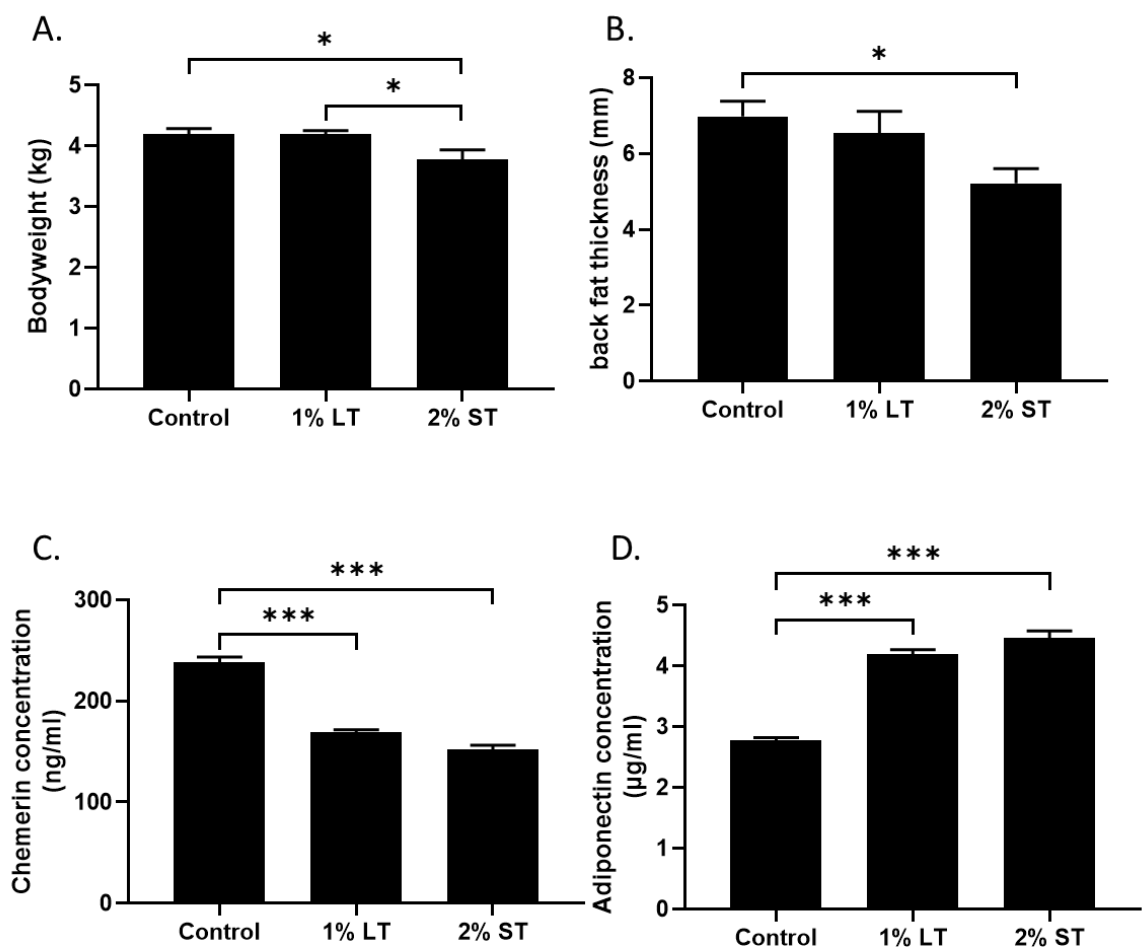

Figure 1. (A) Bodyweight of 3 groups (Control; 1\% LT; 2\% ST) at 40th week of age. (B) The thickness of back fat $(\mathrm{mm})$, as a marker of fat mass, was measured by ultrasonography. (C,D) Plasma concentrations of chemerin and adiponectin were measured at 40th week to evaluate the metabolic status of the animals. ( $\mathrm{n}=10$ animals/group). Control, 1\% Long Treatment, 1\% LT; 2\% Short Treatment, 2\% ST. ${ }^{*}, p<0.05 ; * *, p<0.001$, significant differences with the control. 
Table 1. Analysis of the plasma concentrations at 40th week of age of phospholipids, cholesterol and triglycerides, lactate, glucose, uric acid, calcium and reactive oxygen species (ROS) levels, ROS in the 3 groups (control, 1\% LT, 2\% ST); 1\% Long Treatment, 1\% LT; 2\% Short Treatment, 2\% ST. (n = 10 animals/group).

\begin{tabular}{cccc}
\hline & Control & $\mathbf{1 \% ~ L T ~}$ & 2\% ST \\
\hline Phospholipides $(\mathrm{g} / \mathrm{L})$ & $1.91 \pm 0.04^{\mathrm{a}}$ & $1.74 \pm 0.02^{\mathrm{b}}$ & $1.75 \pm 0.05^{\mathrm{b}}$ \\
Cholesterol $(\mathrm{g} / \mathrm{L})$ & $1.80 \pm 0.06^{\mathrm{a}}$ & $1.92 \pm 0.12^{\mathrm{a}}$ & $1.83 \pm 0.08^{\mathrm{a}}$ \\
Tryglycerides $(\mathrm{g} / \mathrm{L})$ & $7.09 \pm 0.28^{\mathrm{a}}$ & $7.03 \pm 0.28^{\mathrm{a}}$ & $6.71 \pm 0.29^{\mathrm{a}}$ \\
Lactate $(\mu \mathrm{g} / \mathrm{mL})$ & $109.86 \pm 33.81^{\mathrm{a}}$ & $177.5 \pm 25.58^{\mathrm{a}}$ & $106.68 \pm 29.59^{\mathrm{a}}$ \\
Glucose $(\mathrm{mg} / \mathrm{dL})$ & $194.84 \pm 28.26^{\mathrm{a}}$ & $186.36 \pm 32.47^{\mathrm{a}}$ & $189.86 \pm 39.80^{\mathrm{a}}$ \\
Uric acid $(\mathrm{mg} / \mathrm{L})$ & $96.57 \pm 4.08^{\mathrm{a}}$ & $79.55 \pm 3.82^{\mathrm{b}}$ & $76.60 \pm 2.21^{\mathrm{b}}$ \\
Calcium $(\mathrm{mg} / \mathrm{L})$ & $135.71 \pm 4.11^{\mathrm{a}}$ & $151.39 \pm 4.62^{\mathrm{a}}$ & $106.47 \pm 7.05^{\mathrm{b}}$ \\
ROS levels (relative luminescent units) & $0.83 \pm 0.04^{\mathrm{a}}$ & $0.75 \pm 0.07^{\mathrm{ab}}$ & $0.62 \pm 0.05^{\mathrm{b}}$ \\
\hline
\end{tabular}

$\mathrm{a}, \mathrm{b}$ in superscripts indicate significant differences between group $(p<0.05)$.

\subsection{Plasma GSE Phenolic Metabolites}

To determine the metabolic outcome of dietary GSE, we quantified the plasmatic levels of 13 phenolic metabolites (Table 2). The levels of $(+)$-catechin $(p<0.01)$, m-coumaric acid $(p<0.05)$, p-coumaric acid $(p<0.01)$, (-)-epicatechin $(p<0.01)$, 3-hydrobenzoic acid $(p<0.01)$, (-)-epicatechin-3-O-methylether $(p<0.001)$ and 3-hydroxyphenylacetic $(p<0.01)$ increased significantly in the plasma of the hens fed $2 \%$ ST when compared to the control group. The levels of protocatechuic acid, syringic acid, 2-hydroxybenzoic acid, 2,4-dihydroxybenzoic acid, 4-hydroxybenzoic acid and (-)-epicatechin-4-O-methylether did not differ among the three groups $(p>0.05)$. Interestingly, the long-term treatment with a lower amount of GSE did not lead to any increase in the level of any of the phenolic metabolites.

Table 2. Plasma concentrations $(\mathrm{ng} / \mathrm{mL})$ at 40th week of age of the following (poly)phenol metabolites: (+)-catechin, protocatechuic acid, p-coumaric acid, syringic acid, (-)-epicatechin, 2-hydroxybenzoic acid, 5-hydroxybenzoic acid, m-coumaric acid, 2,4 dihydroxybenzoic acid, 4-hydroxybenzoic acid, (-)-epicatechin-3-O-methylether, (-)-epicatechin-4-O-methlether, 3-hydrocyphenylacetic acid. ( $\mathrm{n}=4$ animals for control and 5 animals in 1\% Long Treatment, LT and 2\% Short Treatment, ST groups.

\begin{tabular}{cccc}
\hline Values (ng/mL) & Control & $\mathbf{1 \%} \mathbf{L T}$ & $\mathbf{2 \% ~ S T}$ \\
\hline (+)-catechin & $0.89 \pm 0.13^{\mathrm{a}}$ & $1.22 \pm 0.13^{\mathrm{a}}$ & $7.95 \pm 1.79^{\mathrm{b}}$ \\
(-)-epicatechin & $0.20 \pm 0.12^{\mathrm{a}}$ & $0.61 \pm 0.22^{\mathrm{a}}$ & $3.14 \pm 0.83^{\mathrm{b}}$ \\
(-)-epicatechin-3-O-methylether & $1.85 \pm 0.28^{\mathrm{a}}$ & $4.21 \pm 1.30^{\mathrm{a}}$ & $15.59 \pm 2.44^{\mathrm{b}}$ \\
(-)-epicatechin-4-O-methylether & $1.63 \pm 0.98^{\mathrm{a}}$ & $1.28 \pm 0.31^{\mathrm{a}}$ & $2.36 \pm 0.56^{\mathrm{a}}$ \\
m-coumaric acid & $17.03 \pm 1.96^{\mathrm{a}}$ & $20.25 \pm 6.46^{\mathrm{a}}$ & $60.00 \pm 17.47^{\mathrm{b}}$ \\
p-coumaric acid & $5.76 \pm 1.13^{\mathrm{a}}$ & $6.03 \pm 1.03^{\mathrm{a}}$ & $12.96 \pm 1.39^{\mathrm{b}}$ \\
2-hydroxybenzoic acid & $22.57 \pm 3.36^{\mathrm{a}}$ & $20.37 \pm 2.61^{\mathrm{a}}$ & $23.62 \pm 4.03^{\mathrm{a}}$ \\
3-hydroxybenzoic acid & $43.60 \pm 9.96^{\mathrm{a}}$ & $84.05 \pm 17.62^{\mathrm{a}}$ & $1311.00 \pm 363.10^{\mathrm{b}}$ \\
2.4-dihydroxybenzoic acid & $4.80 \pm 1.48^{\mathrm{a}}$ & $6.37 \pm 1.11^{\mathrm{a}}$ & $3.98 \pm 1.01^{\mathrm{a}}$ \\
4-hydroxybenzoic acid & $17.81 \pm 6.16^{\mathrm{a}}$ & $9.44 \pm 1.81^{\mathrm{a}}$ & $11.35 \pm 3.18^{\mathrm{a}}$ \\
Protocatechuic acid & $8.07 \pm 1.37^{\mathrm{a}}$ & $5.88 \pm 0.50^{\mathrm{a}}$ & $10.00 \pm 1.94^{\mathrm{a}}$ \\
Syringic acid & $6.15 \pm 0.74^{\mathrm{a}}$ & $6.14 \pm 1.53^{\mathrm{a}}$ & $7.54 \pm 1.56^{\mathrm{a}}$ \\
3-hydroxyphenylacetic acid & $112.00 \pm 4.33^{\mathrm{a}}$ & $150.20 \pm 20.72^{\mathrm{a}}$ & $234.80 \pm 14.80^{\mathrm{b}}$ \\
\hline
\end{tabular}




\subsection{Caecal Microbiota Composition}

In order to characterize the caecal microbiota in response to the GSE-enriched diet, we measured diversity indices and determined the caecum microbiota composition at the phylum and family taxonomic levels. At the operational taxonomic unit (OTU) level, the richness did not change among the three groups of hens (Figure 2A), nor did the Inverse Simpson Index, indicating no change in the number of effective taxa in response to GSE enrichment (Figure 2B). The $\beta$-diversity analysis based on Bray-Curtis and Jaccard dissimilarity revealed changes in the caecal microbial community in the presence of GSE in the diet $(p<0.05)$ (Figure 2C,D). At the phylum level, the relative abundance of Proteobacteria, Firmicutes and Epsilonbacteraeota was not significantly affected by GSE enrichment, while the relative abundance of Actinobacteria significantly increased in the $1 \%$ LT group of hens at the expense of the Bacteroidetes (Figure 2E). Analysis at family taxonomical levels revealed that this enhancement in the phylum of Actinobacteria in response to GSE diets was entirely supported by the increase in the relative abundance of Bifidobacteriaceae, which increased significantly in both the $1 \%$ LT and $2 \%$ ST groups (Figure 2F). In the phylum of the Bacteroidetes, the $1 \%$ LT treatment significantly decreased the relative abundance of two minor families, Rikenellaceae and Tannerellaceae (Figure 2G). Within the Firmicutes, both GSE-enriched diets induced a modest but significant increase in the relative abundance of the Lactobacilliaceae and Lachnospiraceae families (Figure $2 \mathrm{H}$ ). In the phylum of the Proteobacteria, the relative abundance of Succinivibrionaceae increased modestly in the caecal content of the hens of the $2 \%$ ST group (Figure 2I).

\subsection{Analysis of Inflammation Markers in Caecal Tissue}

The expression of genes related to gut homeostasis and inflammation was studied in the caeca to evaluate inflammation of intestinal mucosa in the animals. Expression of genes coding for interleukin 22 (IL-22), mucin 2 (Muc 2), tumor growth factor beta (TGF- $\beta$ ) and immunoglobulin A (IgA), which are related to mucosal anti-inflammatory regulation, and inducible nitric oxide synthase (iNOS), interleukin 1 beta (IL-1 $\beta$ ) and interleukin 6 (IL-6), genes linked to pro-inflammatory responses, were analyzed. Expression of IL-22 and Muc 2 increased significantly $(p<0.05)$ in the caecal epithelium of the hens fed $1 \%$ GSE from 4 to 40 weeks of age (Figure 3A,B). Despite a tendency for a lower iNos expression level in the caecum of the hens fed $2 \%$ GSE for 2 weeks, no significant difference was found among the three groups (Figure 3C). For the expression of inflammation gene: interleukin 1 beta (IL-1 $\beta$ ), tumor growth factor beta (TGF- $\beta$ ) and immunoglobulin A (IgA) (Figure 3D-F), no difference was observed between the groups. However, a lower level of IL- 6 was measured in the caecal epithelium of the hens from the $2 \%$ ST group when compared to the control group (Figure 3G, IL-6: $p<0.01$ ). 

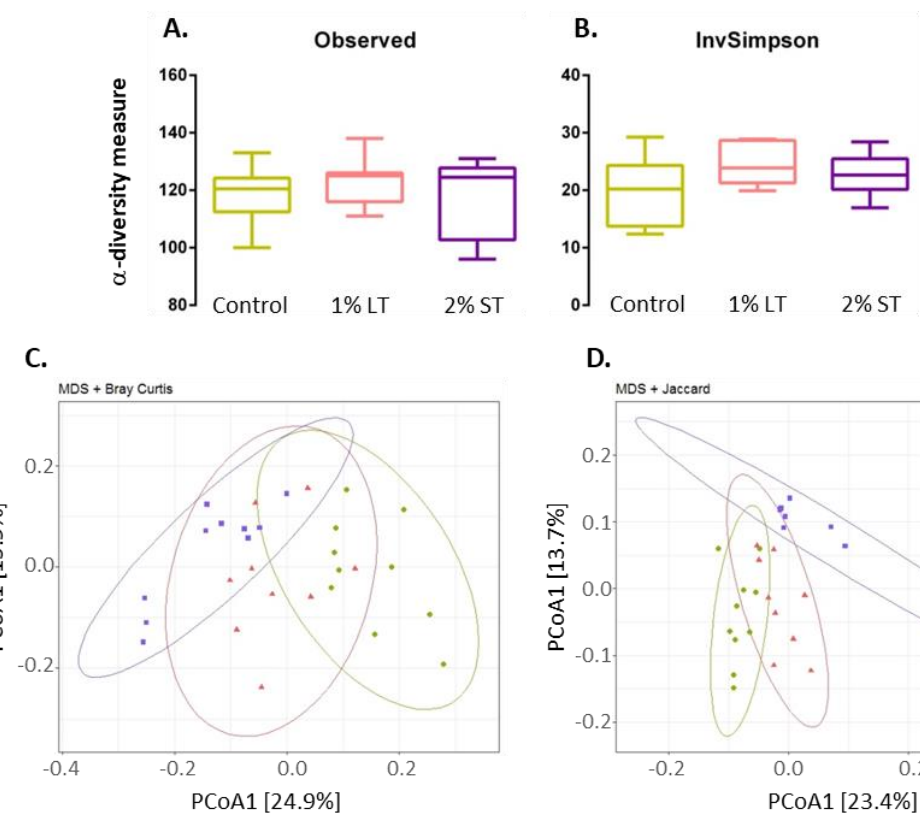

D.
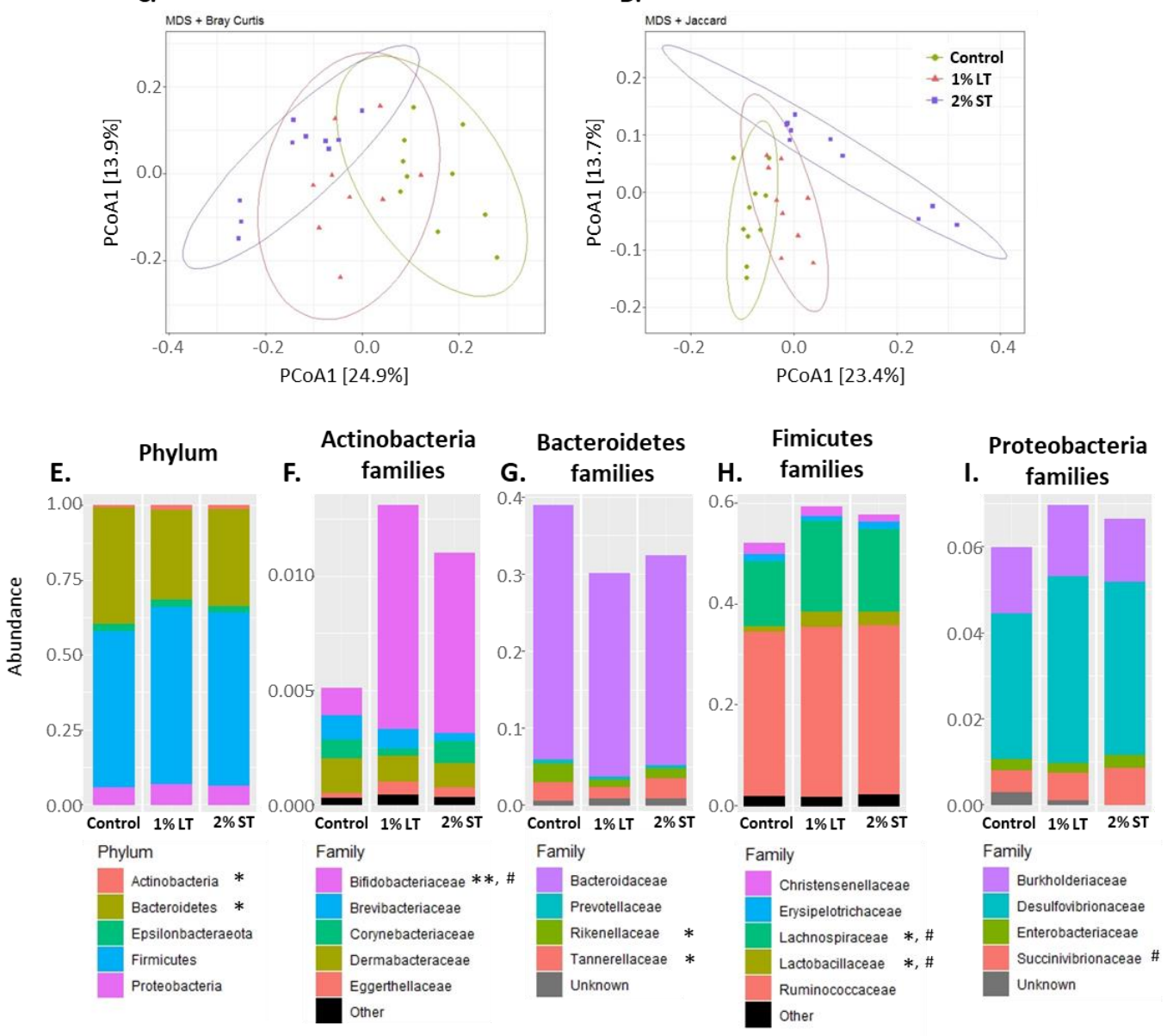

Figure 2. Microbiota composition of the caecum content collected at 40th week of age from hens of 3 groups (Control; 1\% LT; 2\% ST). Evolution of -diversity represented by observed species richness (A) and Inverse Simpson Index (B). Principal coordinates analysis (PCoA) multi-dimensional scaling (MDS) of Bray-Curtis (C) and Jaccard (D) compositional dissimilarity between samples. Average relative abundance at phylum (E) and family (F-I) level in the caecal content of each group. Observed species richness and Inverse Simpson Index values are means \pm SEM compared by one-way ANOVA followed by Tukey's post hoc test. Phylum and family relative abundance data were compared using the Kruskal-Wallis test; * indicates significantly different abundances between Control and 1\% LT (with ${ }^{*} p<0.05$, ${ }^{* *} p<0.01$ ), \# between Control and 2\% ST (with \# $p<0.05$ ). Control, $1 \%$ Long Treatment, $1 \%$ LT; $2 \%$ Short Treatment, $2 \%$ ST. 
A.

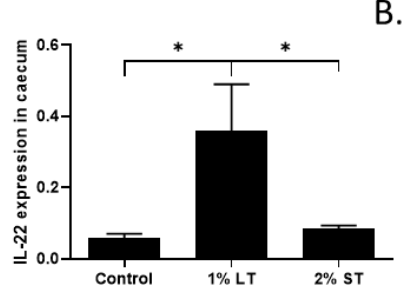

D.

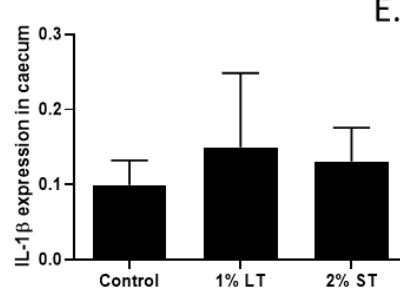

E.
B.

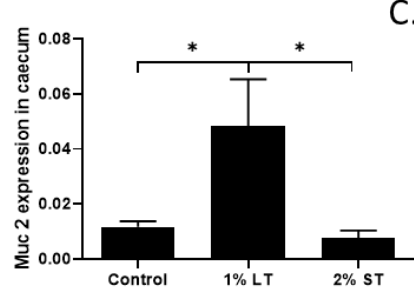

C.

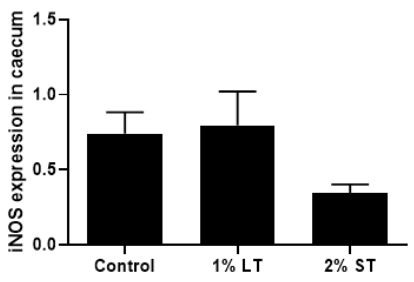

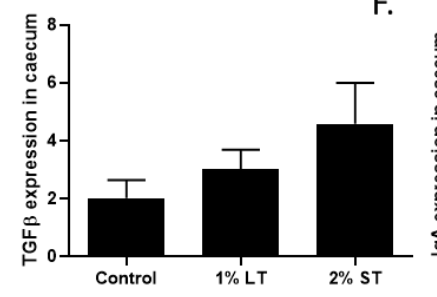

F.

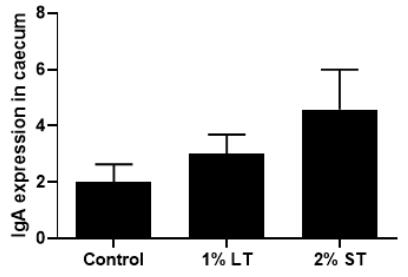

G.

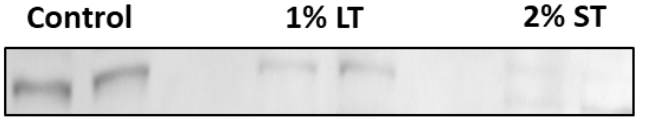

IL-6

$25 \mathrm{kDa}$

Tubulin

$50 \mathrm{kDa}$
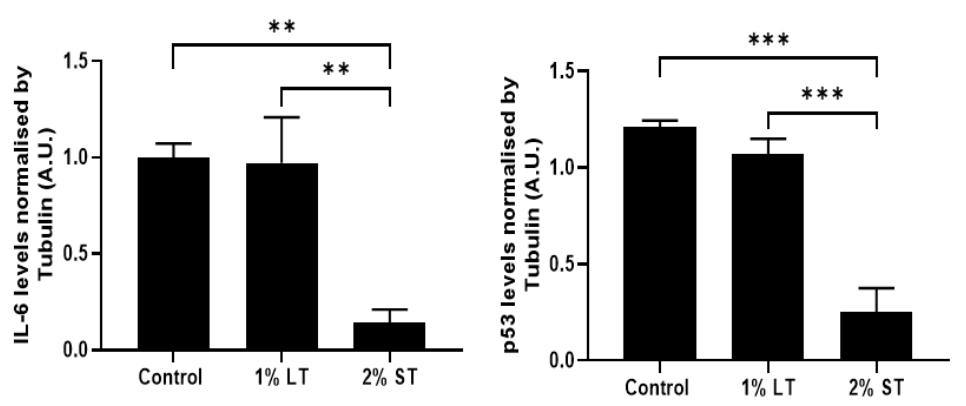

Figure 3. Anti-inflammatory gene expression (A) IL-22, (B) Muc 2, (C) iNOS in the caecal tissue collected at $40^{\text {th }}$ week of age from hens (group: Control; $1 \%$ LT; $2 \%$ ST) as assessed by qPCR. Inflammatory gene expression (D) IL-1 $\beta$, (E) TGF $\beta$, (F) IgA in the caecal tissue collected at 40th week of age from hens (group: Control; 1\% LT; 2\% ST) as assessed by qPCR. ( $n=10$ animals/group) (G) Effect of the grape seed extract (GSE) on the protein level of p53 and IL6 in the caecal tissue as quantified by Western blot. Equal protein loading was checked by reporting the membrane with an anti-tubulin. Representative blots from caecal tissue of the 3 groups are shown, ( $n=5$ animals/group). Control, 1\% Long Treatment, $1 \%$ LT; $2 \%$ Short Treatment, $2 \%$ ST. ${ }^{*}, p<0.05 ;{ }^{* *}, p<0.01 ;{ }^{* *}, p<0.001$, significant differences with the control.

\subsection{Laying Parameters}

The eggs were collected during the last two weeks of both treatments. The supplementation of the diet with GSE did not modify the laying rate of the hens (Figure 4A), but, in the $2 \%$ ST group, the eggs were heavier (Figure 4B, $p<0.001$ ) compared to control and 1\% LT group, and displayed an increase in shelf strength compared to those of the control group (Figure $4 \mathrm{C}, p<0.05$ ) 
A.
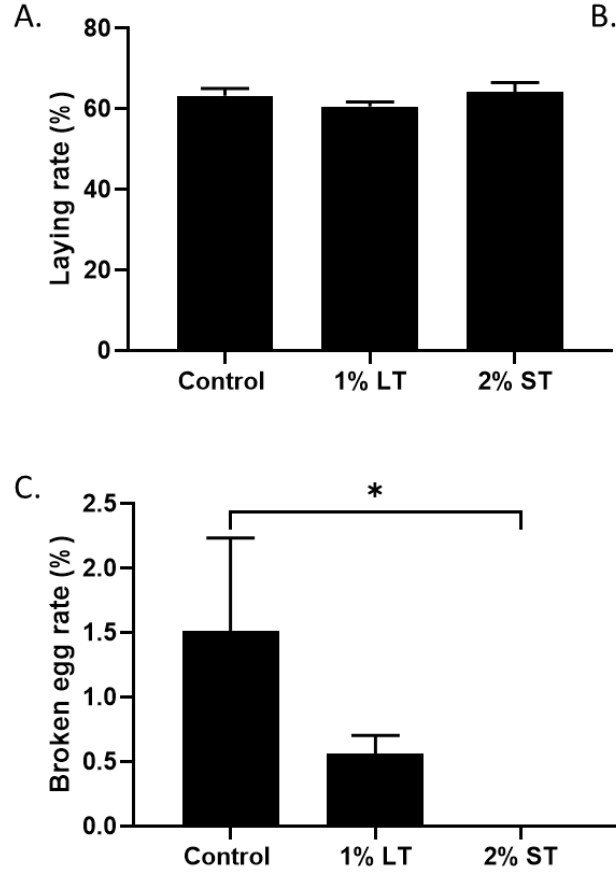

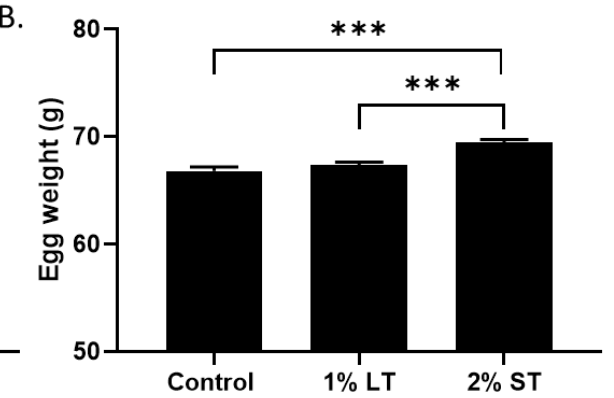

Figure 4. Percentage of laying rate during the collection period (A). Egg weight (g) (B) and solidity (C), collected daily for 2 weeks (group: Control; $1 \%$ LT; $2 \%$ ST). ${ }^{*}, p<0.05 ;{ }^{* * *}, p<0.001$; significant differences with the control. ( $\mathrm{n}=12$ animals/group with at least 120 eggs per group).

\section{Discussion}

The objective of the present study was to evaluate the effects of a long or short exposure to GSE on physiological parameters of parental broiler hens during the reproductive period. The growth physiological and metabolic parameters evaluated demonstrated that GSE addition in the food improved antioxidant status, decreased the fattening of animals and modified the bacterial population in the caecum in association with an improvement of some parameters of intestinal homeostasis (Figure 5).

\subsection{Time/Concentration Exposure}

Previous studies on the effect of grapes on broilers have aimed to focus on meat quality or growth performance. A supplementation of $2.5 \mathrm{~g}$ of GSE/ $\mathrm{kg}$ to 21-day-old chicks had no adverse impact, while $5 \mathrm{~g} / \mathrm{kg}$ retarded their growth rate and decreased their feed conversion [25]. However, the use of grape pomace $(5,10$, and $20 \mathrm{~g} / \mathrm{kg})$ in the diet of broilers from hatching to 40 days old increased growth and feed conversion [42]. These studies showed that the way in which grapes are incorporated into the diet (GSE or grape marc) can have different effects on animal growth. Furthermore, in these cases, supplementation of the grapes was carried out for short periods and not during the breeding period.

In our study, two doses of $10 \mathrm{~g} / \mathrm{kg}$ or $20 \mathrm{~g} / \mathrm{kg}$ of GSE were used during the growth and all adulthood or for a short period of time (2 weeks) only during the reproductive period. Small physiological impacts were observed with $1 \%$ GSE supplementation for 40 weeks, while the use of $2 \%$ GSE for only 2 weeks induced strong changes, specifically by decreasing the fatness, which may be associated with the previous study cited before, showing that a high dose of GSE was associated with growth retardation [25]. The lower fatness was associated with a slight decrease in bodyweight as well as reduced phospholipid and adipokine level. In a previous study, we showed that the measure of back fat thickness by ultrasound is a good predictive marker of the adipose tissue content in the whole body of broilers [6]. Furthermore, in another study, we showed a negative correlation between adiponectin concentrations and fattening, but also a positive correlation with chemerin concentrations in plasma and fatness [43]. So, the use of GSE in the diet could decrease adiposity in female broilers during the 
reproductive period. Reduction in the oxidative stress and fatness could improve the longevity and the quality of the reproductive period of the parental broiler hens.

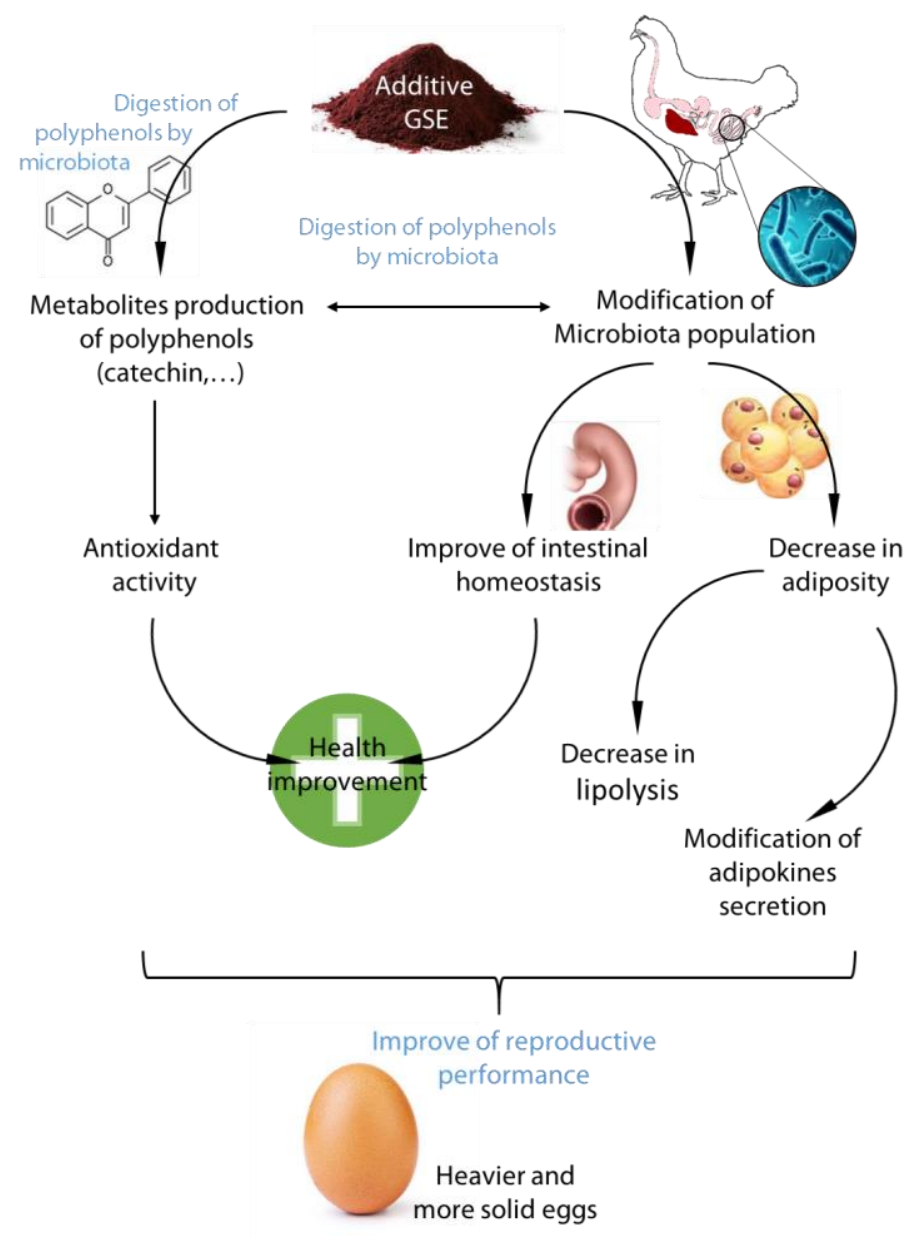

Figure 5. Schema representative of the effects of GSE on microbiota population and adipose tissue in reproductive hens. Representative figure of the diet supplementation of GSE on microbiota population, intestinal homeostasis, and adiposity in reproductive hens. GSE modifies the bacteria content, but bacteria are involved to digest poly and oligomers of polyphenols present in GSE into active monomers with antioxidant activity. The change in the microbial/(poly)phenols environment decreased lipolysis and adipose tissue and improved intestine homeostasis and the antioxidant status.

\subsection{Microbiota and GSE}

The effects on growth in response to an average dose are all the more surprising, since most of the (poly)phenols contained in the grape seed are highly polymerized proanthocyanidins that are difficult to assimilate [44]. They could be absorbed only as monomers (catechin, epicatechin) or oligomers (proanthocyanidin) [45]. The monomers are produced by the degradation of GSE by gut microbiota. In rats, grape polyphenols (procyanidin B1 or procyanidin A2) are converted into dimers by the intestinal microorganisms [46]. In pigs, 6 days of feeding with 1\% GSE is associated with an increase in secondary monomer metabolites, such as (-)epicatechin, (+)-catechins or 3-hydroxybenzoic acid, in the feces [47]. In chickens, $2.5 \%$ to $5 \%$ of a whole grape extract supplementation was also associated with an increase in microbial-derived phenolic metabolites $((+)$-catechin or (-)-epicatechin) in ileal digesta and excreta [48].

In the present study, we measured phenolic compounds in the blood, thus showing whether or not GSE is digested by the microbiota. Interestingly, $2 \%$ ST GSE supplementation led to elevated levels of by-products of polyphenol, likely resulting from proanthocyanidin degradation by gut microbiota 
like catechins or epicatechins, whereas 1\% LT GSE supplementation had no effect. The use of 1\% GSE in the diet may have been insufficient to be detected significantly in the plasma. Even the control group displayed low levels of phenolic compounds, likely originating from the wheat and soya of the diet [49]. These increases in by-products of polyphenols in animals with 2\% GSE were associated with a better antioxidant status, as observed by the low ROS content in plasma. The antioxidant characteristics of grape, grape products and their by-products contain scavenging free radicals which form some complexes with metal ions to prevent and reduce the development of ROS [50]. Catechins have been described as possessing great antioxidant potential and can decrease oxidative stress in the organism by its ROS scavenger activity or by its potential role in the induction of antioxidant enzymes or the inhibition of pro-oxidant enzymes [51]. The ROS level is a reflection of the stress of an animal [52,53]. Several studies have shown that a decrease in the oxidative status of an animal can be associated with a decrease in fattening [54,55]. The analysis of the body composition revealed a decrease in the bodyweight [56]. However, several markers associated with the diminution of the adipose tissue mass have been shown after $1 \%$ or $2 \%$ GSE exposure: reduction in the dorsal fattening level by ultrasound [6], weight of adipose mass, modification in adipokine levels: chemerin decrease and adiponectin increase [43], decrease in phospholipids and uric acid levels in plasma. Uric acid level has also been shown to be a marker of adiposity, because high secretion was observed in obese mice [57]. Similar observations have been measured in caeca tissue with low phospholipids, triglycerides, cholesterol and ATP, suggesting a decrease in lipogenesis (Supplemental Data 3). Two hypotheses for the decrease in fattening could be suggested: firstly, a direct effect of GSE (and its by-products) on different cells (adipose tissue, muscle, etc.); or secondly, a change in microbiota population [58]. Indeed, some findings have shown that obesity is correlated with the Firmicutes/Bacteroidetes ratio [29,59,60]. In these studies, the researchers showed that the increase in Firmicutes and the decrease in Bacteroidetes were associated with obesity. However, in the present study, the level of Firmicutes did not vary and a decrease in Bacteroidetes was observed. Although the abundance of Firmicutes is similar, the composition of bacteria in this phylum was modified with an increase in Lactobacillus levels. Lactobacillus used as a probiotic in the diet of mice or rats can attenuate the overweight and elevate the adiponectin secretion associated to the excess of adipose tissue [61,62]. Studies have shown that grape and its by-products (like catechin) can stimulate the growth of Lactobacillus in the intestine of animals $[63,64]$. Thus, the modification of the microbiota by GSE could be a cause of the reduction in the fat storage in hens [65]. Finally, the increase in by-products of polyphenols in plasma, caused by the consumption of $2 \%$ GSE during a short period, can be associated with a decrease in adiposity and an improvement in welfare.

In addition to its ability to enhance the bioavailability of (poly)phenols, the gut microbiota composition adaptation to the GSE supplementation could also contribute to the improvement of physiological and metabolic parameters. First of all, the changes observed in the composition of the microbiota were more pronounced in the group that received 1\% GSE for 36 weeks than in the group that received $2 \%$ GSE for 2 weeks.

The results show that the Actinobacteria population increased and Bacteroidetes decreased in hens exposed to 1\% GSE for 36 weeks. Bacteroidetes have been associated with negative health outcomes such as irritable bowel syndrome, diarrhea and chronic inflammatory bowel disease [66,67]; therefore, the decrease in Bacteroidetes in the caeca of hens improves the intestinal health in our study. GSE supplementation ( 1 or $2 \%$ ) was also associated with the increase in the relative abundance of Lactobacillus, Lachnospirales and Bifidobacteriaceae. These data are in agreement with earlier studies that characterized the intestinal microbiota adaptation to GSE in livestock animals [47,68]. Lactobacillus is used as a probiotic in broilers, since it has been shown to have a beneficial effect on growth, carcass quality and to prevent intestinal infection [69]. Lactobacillus reuteri KUB-AC5 exposure immediately after hatching allowed long-term enrichment in Lactobacillus and long-term reduction in Proteobacteria and other non-beneficial bacteria [70]. As previously described, Bifidobacteria also boost carbohydrate digestion [71] and improve intestinal heath by reducing diarrhea or inflammatory bowel disease in 
humans [72-75]. These data obtained with the use of GSE in the diet were part of an improvement in welfare.

\subsection{Improvement of Caecal Homeostasis}

The modification in the bacterial population and presence of polyphenols in the caecum appeared to improve the intestinal homeostasis with a better antioxidant status and decrease in the expression of pro-inflammatory factors. The results are associated with a higher expression of IL-22 and Muc-2 for the long GSE exposure. Indeed, assimilable phenolic compounds such as catechin are able to regulate the growth of some bacterial species, probably via an interaction with enterocytes activity [76]. The short exposure at the 38th week of age is possibly too late (at adult age) to measure an effect on gene expression by epithelial or goblet cells. However, this hypothesis needs to be confirmed in the future.

In mice, IL-22 is known to ameliorate intestinal homeostasis by enhancing STAT3 activation and the expression of mucus-associated molecules by goblet cells to limit intestinal inflammation [77]. The mucus barrier plays such a fundamental role in intestinal functions and homeostasis; Muc-2 also promotes the production of mucin and has an active role in regulating mucosal immunity [78]. The use of GSE at $0.1 \%$ GSE (w/v) for 12 weeks in female mice increased the colonic goblet cell density that was associated with increased mRNA expression of Muc-2 [79].

The pro-inflammatory markers, IL-1 $\beta$ and IgA, play a central role in the intestinal inflammation amplification cascade by increasing the permeability of the intestinal epithelial junction [80]. We noted that these genes are not affected by GSE exposure, whatever the time of exposure, but IL6, identified as a crucial regulator of inflammatory responses [81], diminished significantly with $2 \%$ GSE exposure for 2 weeks. The markers of cell death measured by p53 [82] or cleaved caspase 3 activity were at lower levels in the presence of GSE, reinforcing the well-being status of intestine cells and good homeostasis.

\section{Conclusions}

Nowadays, the use of natural products in food is of great interest for the development of agroecology strategies for breeders and to conserve broiler performances. However, studies on broilers have been performed on up to 35-day old chickens but not on adults in the reproductive period. In our study, grape and, more particularly, grape seed extract were studied in the diet $[56,83]$. The antioxidant property of GSE has been reported to improve the total antioxidant status in the plasma of Japanese quail [84] and antioxidant capacity in the blood of broilers [85].

In this study, we have shown that a diet enriched in GSE during the reproductive period can be beneficial for intestine health, which impacts different functions of the organism (behavior, health, reproduction) (Figure 5). In brief, until changes in the selection of broiler lines appear, a short-term choice could be the use of GSE in the diet to improve animal welfare (adiposity and oxidative status). The long-term choice could be to improve the inflammatory status of the gut. Moreover, this study opens up new directions by selecting specific probiotics based on the modifications of the microbiota observed, which could mimic the beneficial effects of GSE in hens. Finally, this strategy of using natural molecules in the diet of a highly selected line (broiler) over a long breeding period for this breed (40 weeks) has shown beneficial effects quickly, and could be of use for other strains of poultry, bred for muscle quality or egg production.

Supplementary Materials: Supplementary materials can be found at http://www.mdpi.com/2076-2607/8/8/1141/s1. Supplemental Data S1: A scheme of the protocol for experimental trials. From the first day to the 4th week, all chicks received an ad libitum diet (free access to food). At 4th week, two groups of hens were separated in function of 2 types of diets: control diet and the same diet supplemented with GSE at $1 \%$ of total diet. At week 38 of age, a third group was created from the control group and received the diet supplemented with $2 \%$ GSE for two weeks. Supplemental Data S2: Oligonucleotide primer sequences.

Author Contributions: Conceptualization, J.G.; investigation, J.G.; formal analysis, J.G., V.D., A.R.-M., Y.X., A.C., A.R., R.G., O.Z., C.P., M.M., C.S., E.V., A.B., C.R., J.D. and P.F.; data curation, J.G., V.D., A.R.-M., Y.X., A.C., A.R., 
R.G., O.Z., C.P., M.M., C.S., E.V., A.B., C.R., J.D.; Writing - review \& editing, J.G., V.D. and P.F.; supervision, J.D. and P.F.; funding acquisition, J.D. and P.F. All authors have read and agreed to the published version of the manuscript.

Funding: This research received funding from the APR Région Centre Val de Loire, France (PREVADI and OXYFERTI).

Acknowledgments: The authors like to thank the staff of the Poultry Breeding Facilities (INRA, UE1295 Pôle d'Expérimentation Avicole de Tours, Nouzilly, France) for animal care and animal expertise and more particularly Marine Chahnamian, Patrice Ganier, and Olivier Callut (UEPAT). We thank the Region Centre Val de Loire to fund the project PREVADI and OXYFERTI. We thanks Clemens Laurans from Agro-Bio to develop antibodies (2 Allée de la Chavannerie, 45240 La Ferté Saint Aubin, France), and Marine Cirot (UEPAO). Acknowledgments are also extended to Anthony Sullivan, Chris Titman and Neil Loftus from Shimadzu UK Ltd. for their support on the LC-MS/MS instrument.

Conflicts of Interest: The authors declare that there are no conflicts of interest. The funders had no role in the design of the study; in the collection, analyses, or interpretation of data; in the writing of the manuscript; or in the decision to publish the results.

\section{References}

1. Havenstein, G.B.; Ferket, P.R.; Qureshi, M.A. Carcass composition and yield of 1957 versus 2001 broilers when fed representative 1957 and 2001 broiler diets. Poult. Sci. 2003, 82, 1509-1518. [CrossRef] [PubMed]

2. Marseglia, L.; Manti, S.; D’Angelo, G.; Nicotera, A.; Parisi, E.; Di Rosa, G.; Gitto, E.; Arrigo, T. Oxidative Stress in Obesity: A Critical Component in Human Diseases. Int. J. Mol. Sci. 2014, 16, 378-400. [CrossRef] [PubMed]

3. Heck, A.; Onagbesan, O.; Tona, K.; Metayer, S.; Putterflam, J.; Jego, Y.; Trevidy, J.J.; Decuypere, E.; Williams, J.; Dr, M.P.; et al. Effects of ad libitum feeding on performance of different strains of broiler breeders. Br. Poult. Sci. 2004, 45, 695-703. [CrossRef]

4. Hocking, P.M.; Duff, S.R.I. Musculo-Skeletal lesions in adult male broiler breeder fowls and their relationships with body weight and fertility at 60 weeks of age. Br. Poult. Sci. 1989, 30, 777-784. [CrossRef] [PubMed]

5. Richards, M.P.; Proszkowiec-Weglarz, M. Mechanisms Regulating Feed Intake, Energy Expenditure, and Body Weight in Poultry. Poult. Sci. 2007, 86, 1478-1490. [CrossRef]

6. Grandhaye, J.; Lecompte, F.; Staub, C.; Venturi, E.; Plotton, I.; Cailleau-Audouin, E.; Ganier, P.; Ramé, C.; Brière, S.; Dupont, J.; et al. Assessment of the body development kinetic of broiler breeders by non-invasive imaging tools. Poult. Sci. 2019, 98, 4140-4152. [CrossRef]

7. Onyango, E.M.; Hester, P.Y.; Stroshine, R.; Adeola, O. Bone densitometry as an indicator of percentage tibia ash in broiler chicks fed varying dietary calcium and phosphorus levels. Poult. Sci. 2003, 82, 1787-1791. [CrossRef]

8. Valable, A.S.; Narcy, A.; Duclos, M.J.; Pomar, C.; Page, G.; Nasir, Z.; Magnin, M.; Létourneau-Montminy, M.P. Effects of dietary calcium and phosphorus deficiency and subsequent recovery on broiler chicken growth performance and bone characteristics. Animal 2018, 12, 1555-1563. [CrossRef]

9. Urso, U.R.A.; Dahlke, F.; Maiorka, A.; Bueno, I.J.M.; Schneider, A.F.; Surek, D.; Rocha, C. Vitamin E and selenium in broiler breeder diets: Effect on live performance, hatching process, and chick quality. Poult. Sci. 2015, 94, 976-983. [CrossRef]

10. Surai, P.F. Selenium in poultry nutrition 2. Reproduction, egg and meat quality and practical applications. World. Poultry. Sci. J. 2002, 58, 431-450. [CrossRef]

11. Hocking, P.M. Effects of body weight at sexual maturity and the degree and age of restriction during rearing on the ovarian follicular hierarchy of broiler breeder females. Br. Poult. Sci. 1993, 34, 793-801. [CrossRef]

12. Mellouk, N.; Ramé, C.; Marchand, M.; Staub, C.; Touzé, J.-L.; Venturi, É.; Mercerand, F.; Travel, A.; Chartrin, P.; Lecompte, F.; et al. Effect of different levels of feed restriction and fish oil fatty acid supplementation on fat deposition by using different techniques, plasma levels and mRNA expression of several adipokines in broiler breeder hens. PLoS ONE 2018, 13, e0191121. [CrossRef] [PubMed]

13. Naczk, M.; Shahidi, F. Phenolics in cereals, fruits and vegetables: Occurrence, extraction and analysis. J. Pharmaceut. Biomed. 2006, 41, 1523-1542. [CrossRef] [PubMed]

14. Villaño, D.; Fernández-Pachón, M.S.; Troncoso, A.M.; García-Parrilla, M.C. Comparison of antioxidant activity of wine phenolic compounds and metabolites in vitro. Anal. Chim. Acta. 2005, 538, 391-398. [CrossRef] 
15. García-Lafuente, A.; Guillamón, E.; Villares, A.; Rostagno, M.A.; Martínez, J.A. Flavonoids as anti-inflammatory agents: Implications in cancer and cardiovascular disease. Inflamm. Res. 2009, 58, 537-552. [CrossRef] [PubMed]

16. McCullough, M.L.; Peterson, J.J.; Patel, R.; Jacques, P.F.; Shah, R.; Dwyer, J.T. Flavonoid intake and cardiovascular disease mortality in a prospective cohort of US adults. Am. J. Clin. Nutr. 2012, 95, 454-464. [CrossRef]

17. Weaver, C.M.; Alekel, D.L.; Ward, W.E.; Ronis, M.J. Flavonoid Intake and Bone Health. Nutr. Gerontol. Geriatr. 2012, 31, 239-253. [CrossRef]

18. Kawabata, K.; Yoshioka, Y.; Terao, J. Role of Intestinal Microbiota in the Bioavailability and Physiological Functions of Dietary Polyphenols. Molecules 2019, 24, 370. [CrossRef]

19. Choy, Y.Y.; Jaggers, G.K.; Oteiza, P.I.; Waterhouse, A.L. Bioavailability of Intact Proanthocyanidins in the Rat Colon after Ingestion of Grape Seed Extract. J. Agric. Food Chem. 2013, 61, 121-127. [CrossRef]

20. Frolinger, T.; Sims, S.; Smith, C.; Wang, J.; Cheng, H.; Faith, J.; Ho, L.; Hao, K.; Pasinetti, G.M. The gut microbiota composition affects dietary polyphenols-mediated cognitive resilience in mice by modulating the bioavailability of phenolic acids. Sci. Rep. 2019, 9, 1-10. [CrossRef]

21. Scalbert, A.; Morand, C.; Manach, C.; Rémésy, C. Absorption and metabolism of polyphenols in the gut and impact on health. Biomed. Pharmacother. 2002, 56, 276-282. [CrossRef]

22. Tian, L.; Tan, Y.; Chen, G.; Wang, G.; Sun, J.; Ou, S.; Chen, W.; Bai, W. Metabolism of anthocyanins and consequent effects on the gut microbiota. Crit. Rev. Food Sci. Nutr. 2019, 59, 982-991. [CrossRef] [PubMed]

23. Wang, M.L.; Suo, X.; Gu, J.H.; Zhang, W.W.; Fang, Q.; Wang, X. Influence of Grape Seed Proanthocyanidin Extract in Broiler Chickens: Effect on Chicken Coccidiosis and Antioxidant Status. Poult. Sci. 2008, 87, 2273-2280. [CrossRef] [PubMed]

24. Banaszkiewicz, T.; Białek, A.; Tokarz, A.; Kaszperuk, K. Effect of dietary grape and pomegranate seed oil on the post-slaughter value and physicochemical properties of muscles of broiler chickens. Acta Sci. Pol. Technol. Aliment. 2018, 17, 199-209. [CrossRef]

25. Chamorro, S.; Viveros, A.; Centeno, C.; Romero, C.; Arija, I.; Brenes, A. Effects of dietary grape seed extract on growth performance, amino acid digestibility and plasma lipids and mineral content in broiler chicks. Animal 2013, 7, 555-561. [CrossRef] [PubMed]

26. Maslowski, K.M.; Mackay, C.R. Diet, gut microbiota and immune responses. Nat. Immunol. 2010, 12, 5-9. [CrossRef]

27. Etxeberria, U.; Fernández-Quintela, A.; Milagro, F.I.; Aguirre, L.; Martínez, J.A.; Portillo, M.P. Impact of Polyphenols and Polyphenol-Rich Dietary Sources on Gut Microbiota Composition. J. Agric. Food Chem. 2013, 61, 9517-9533. [CrossRef] [PubMed]

28. Espley, R.V.; Butts, C.A.; Laing, W.A.; Martell, S.; Smith, H.; McGhie, T.K.; Zhang, J.; Paturi, G.; Hedderley, D.; Bovy, A.; et al. Dietary Flavonoids from Modified Apple Reduce Inflammation Markers and Modulate Gut Microbiota in Mice. J. Nutr. 2014, 144, 146-154. [CrossRef] [PubMed]

29. Liu, W.; Zhao, S.; Wang, J.; Shi, J.; Sun, Y.; Wang, W.; Ning, G.; Hong, J.; Liu, R. Grape seed proanthocyanidin extract ameliorates inflammation and adiposity by modulating gut microbiota in high-fat diet mice. Mol. Nutr. Food Res. 2017, 61, 1601082. [CrossRef]

30. Ley, R.E.; Turnbaugh, P.J.; Klein, S.; Gordon, J.I. Microbial ecology: Human gut microbes associated with obesity. Nature 2006, 444, 1022-1023. [CrossRef] [PubMed]

31. Turnbaugh, P.J.; Ley, R.E.; Mahowald, M.A.; Magrini, V.; Mardis, E.R.; Gordon, J.I. An obesity-associated gut microbiome with increased capacity for energy harvest. Nature 2006, 444, 1027-1031. [CrossRef] [PubMed]

32. Zhang, P.; Yan, T.; Wang, X.; Kuang, S.; Xiao, Y.; Lu, W.; Bi, D. Probiotic mixture ameliorates heat stress of laying hens by enhancing intestinal barrier function and improving gut microbiota. Ital. J. Anim. Sci. 2017, 16, 292-300. [CrossRef]

33. Feliciano, R.P.; Boeres, A.; Massacessi, L.; Istas, G.; Ventura, M.R.; Nunes Dos Santos, C.; Heiss, C.; Rodriguez-Mateos, A. Identification and quantification of novel cranberry-derived plasma and urinary (poly)phenols. Arch. Biochem. Biophys. 2016, 599, 31-41. [CrossRef] [PubMed]

34. Rodriguez-Mateos, A.; Feliciano, R.P.; Boeres, A.; Weber, T.; dos Santos, C.N.; Ventura, M.R.; Heiss, C. Cranberry (poly)phenol metabolites correlate with improvements in vascular function: A double-blind, randomized, controlled, dose-response, crossover study. Mol. Nutr. Food Res. 2016, 60, 2130-2140. [CrossRef] 
35. Furet, J.-P.; Firmesse, O.; Gourmelon, M.; Bridonneau, C.; Tap, J.; Mondot, S.; Doré, J.; Corthier, G. Comparative assessment of human and farm animal faecal microbiota using real-time quantitative PCR. FEMS Microbiol. Ecol. 2009, 68, 351-362. [CrossRef]

36. Kozich, J.J.; Westcott, S.L.; Baxter, N.T.; Highlander, S.K.; Schloss, P.D. Development of a Dual-Index Sequencing Strategy and Curation Pipeline for Analyzing Amplicon Sequence Data on the MiSeq Illumina Sequencing Platform. Appl. Environ. Microbiol. 2013, 79, 5112-5120. [CrossRef]

37. Escudié, F.; Auer, L.; Bernard, M.; Mariadassou, M.; Cauquil, L.; Vidal, K.; Maman, S.; Hernandez-Raquet, G.; Combes, S.; Pascal, G. FROGS: Find, Rapidly, OTUs with Galaxy Solution. Bioinformatics. 2018, 34, 1287-1294. [CrossRef]

38. Bokulich, N.A.; Subramanian, S.; Faith, J.J.; Gevers, D.; Gordon, J.I.; Knight, R.; Mills, D.A.; Caporaso, J.G. Quality-filtering vastly improves diversity estimates from Illumina amplicon sequencing. Nat. Methods. 2013, 10, 57-59. [CrossRef]

39. Diot, M.; Reverchon, M.; Rame, C.; Froment, P.; Brillard, J.-P.; Brière, S.; Levêque, G.; Guillaume, D.; Dupont, J. Expression of adiponectin, chemerin and visfatin in plasma and different tissues during a laying season in turkeys. Reprod. Biol. Endocrinol. 2015, 13. [CrossRef]

40. McMurdie, P.J.; Holmes, S. phyloseq: An R package for reproducible interactive analysis and graphics of microbiome census data. PLoS ONE. 2013, 8, e61217. [CrossRef]

41. Wickham, H. Ggplot2: Elegant Graphics for Data Analysis; Springer: Berlin/Heidelberg, Germany, 2016; ISBN 978-3-319-24277-4.

42. Pascariu, S.M.; Pop, I.M.; Simeanu, D.; Pavel, G.; Solcan, C.; Pascariu, S.M.; Pop, I.M.; Simeanu, D.; Pavel, G.; Solcan, C. Effects of Wine by-Products on Growth Performance, Complete Blood Count and Total Antioxidant Status in Broilers. Braz. J. Poultry Sci. 2017, 19, 191-202. [CrossRef]

43. Mellouk, N.; Ramé, C.; Barbe, A.; Grandhaye, J.; Froment, P.; Dupont, J. Chicken Is a Useful Model to Investigate the Role of Adipokines in Metabolic and Reproductive Diseases. Int. J. Endocrinol. 2018, 2018, 4579734. [CrossRef]

44. Vivas, N.; Nonier, M.-F.; de Gaulejac, N.V.; Absalon, C.; Bertrand, A.; Mirabel, M. Differentiation of proanthocyanidin tannins from seeds, skins and stems of grapes (Vitis vinifera) and heartwood of Quebracho (Schinopsis balansae) by matrix-assisted laser desorption/ionization time-of-flight mass spectrometry and thioacidolysis/liquid chromatography/electrospray ionization mass spectrometry. Anal. Chim. Acta. 2004, 513, 247-256. [CrossRef]

45. Ky, I.; Lorrain, B.; Kolbas, N.; Crozier, A.; Teissedre, P.-L. Wine by-Products: Phenolic Characterization and Antioxidant Activity Evaluation of Grapes and Grape Pomaces from Six Different French Grape Varieties. Molecules 2014, 19, 482-506. [CrossRef]

46. Ge, Z.; Dong, X.; Zhu, W.; Zhang, Y.; Li, C. Metabolites and Changes in Antioxidant Activity of A-Type and B-Type Proanthocyanidin Dimers after Incubation with Rat Intestinal Microbiota. J. Agric. Food Chem. 2015, 63, 8991-8998. [CrossRef] [PubMed]

47. Choy, Y.Y.; Quifer-Rada, P.; Holstege, D.M.; Frese, S.A.; Calvert, C.C.; Mills, D.A.; Lamuela-Raventos, R.M.; Waterhouse, A.L. Phenolic metabolites and substantial microbiome changes in pig feces by ingesting grape seed proanthocyanidins. Food Funct. 2014, 5, 2298-2308. [CrossRef]

48. Chamorro, S.; Romero, C.; Brenes, A.; Sánchez-Patán, F.; Bartolomé, B.; Viveros, A.; Arija, I. Impact of a sustained consumption of grape extract on digestion, gut microbial metabolism and intestinal barrier in broiler chickens. Food Funct. 2019, 10, 1444-1454. [CrossRef] [PubMed]

49. Rothwell, J.A.; Perez-Jimenez, J.; Neveu, V.; Medina-Remón, A.; M’hiri, N.; García-Lobato, P.; Manach, C.; Knox, C.; Eisner, R.; Wishart, D.S.; et al. Phenol-Explorer 3.0: A major update of the Phenol-Explorer database to incorporate data on the effects of food processing on polyphenol content. Database 2013, 2013, bat070. [CrossRef]

50. Surai, P.F. Polyphenol compounds in the chicken/animal diet: From the past to the future. J. Anim. Physiol. An. N. 2014, 98, 19-31. [CrossRef]

51. Bernatoniene, J.; Kopustinskiene, D.M. The Role of Catechins in Cellular Responses to Oxidative Stress. Molecules 2018, 23, 965. [CrossRef]

52. Dröge, W. Free radicals in the physiological control of cell function. Physiol. Rev. 2002, 82, 47-95. [CrossRef] [PubMed] 
53. Altan, Ö.; Pabuçcuoğlu, A.; Altan, A.; Konyalioğlu, S.; Bayraktar, H. Effect of heat stress on oxidative stress, lipid peroxidation and some stress parameters in broilers. Br. Poult. Sci. 2003, 44, 545-550. [CrossRef] [PubMed]

54. Lin, C.F.; Asghar, A.; Gray, J.I.; Buckley, D.J.; Booren, A.M.; Crackel, R.L.; Flegal, C.J. Effects of oxidised dietary oil and antioxidant supplementation on broiler growth and meat stability. Br. Poult. Sci. 1989, 30, 855-864. [CrossRef]

55. Huang, J.; Zhang, Y.; Zhou, Y.; Zhang, Z.; Xie, Z.; Zhang, J.; Wan, X. Green Tea Polyphenols Alleviate Obesity in Broiler Chickens through the Regulation of Lipid-Metabolism-Related Genes and Transcription Factor Expression. J. Agric. Food Chem. 2013, 61, 8565-8572. [CrossRef] [PubMed]

56. Barbe, A.; Mellouk, N.; Ramé, C.; Grandhaye, J.; Staub, C.; Venturi, E.; Cirot, M.; Petit, A.; Anger, K.; Chahnamian, M.; et al. A grape seed extract maternal dietary supplementation in reproductive hens reduces oxidative stress associated to modulation of plasma and tissue adipokines expression and improves viability of offsprings. PLOS ONE 2020, 15, e0231131. [CrossRef] [PubMed]

57. Tsushima, Y.; Nishizawa, H.; Tochino, Y.; Nakatsuji, H.; Sekimoto, R.; Nagao, H.; Shirakura, T.; Kato, K.; Imaizumi, K.; Takahashi, H.; et al. Uric acid secretion from adipose tissue and its increase in obesity. J. Biol. Chem. 2013, 288, 27138-27149. [CrossRef] [PubMed]

58. den Besten, G.; van Eunen, K.; Groen, A.K.; Venema, K.; Reijngoud, D.-J.; Bakker, B.M. The role of short-chain fatty acids in the interplay between diet, gut microbiota, and host energy metabolism. J. Lipid Res. 2013, 54, 2325-2340. [CrossRef]

59. Masumoto, S.; Terao, A.; Yamamoto, Y.; Mukai, T.; Miura, T.; Shoji, T. Non-absorbable apple procyanidins prevent obesity associated with gut microbial and metabolomic changes. Sci. Rep. 2016, 6. [CrossRef]

60. Turnbaugh, P.J.; Hamady, M.; Yatsunenko, T.; Cantarel, B.L.; Duncan, A.; Ley, R.E.; Sogin, M.L.; Jones, W.J.; Roe, B.A.; Affourtit, J.P.; et al. A core gut microbiome in obese and lean twins. Nature 2009, 457, 480-484. [CrossRef]

61. Kim, S.-W.; Park, K.-Y.; Kim, B.; Kim, E.; Hyun, C.-K. Lactobacillus rhamnosus GG improves insulin sensitivity and reduces adiposity in high-fat diet-fed mice through enhancement of adiponectin production. Biochem. Biophys. Res. Commun. 2013, 431, 258-263. [CrossRef]

62. Kang, J.-H.; Yun, S.-I.; Park, H.-O. Effects of Lactobacillus gasseri BNR17 on body weight and adipose tissue mass in diet-induced overweight rats. J. Microbiol. 2010, 48, 712-714. [CrossRef] [PubMed]

63. Pozuelo, M.J.; Agis-Torres, A.; Hervert-Hernández, D.; Elvira López-Oliva, M.; Muñoz-Martínez, E.; Rotger, R.; Goñi, I. Grape Antioxidant Dietary Fiber Stimulates Lactobacillus Growth in Rat Cecum. J. Food Sci. 2012, 77, H59-H62. [CrossRef]

64. Nash, V.; Ranadheera, C.S.; Georgousopoulou, E.N.; Mellor, D.D.; Panagiotakos, D.B.; McKune, A.J.; Kellett, J.; Naumovski, N. The effects of grape and red wine polyphenols on gut microbiota-A systematic review. Food Res. Int. 2018, 113, 277-287. [CrossRef] [PubMed]

65. Bäckhed, F.; Ding, H.; Wang, T.; Hooper, L.V.; Koh, G.Y.; Nagy, A.; Semenkovich, C.F.; Gordon, J.I. The gut microbiota as an environmental factor that regulates fat storage. Proc. Natl. Acad. Sci. USA 2004, 101, 15718-15723. [CrossRef]

66. Hungin, A.P.S.; Mulligan, C.; Pot, B.; Whorwell, P.; Agréus, L.; Fracasso, P.; Lionis, C.; Mendive, J.; Philippart de Foy, J.-M.; Rubin, G.; et al. Systematic review: Probiotics in the management of lower gastrointestinal symptoms in clinical practice-An evidence-based international guide. Aliment. Pharmacol. Ther. 2013, 38, 864-886. [CrossRef] [PubMed]

67. Dueñas, M.; Muñoz-González, I.; Cueva, C.; Jiménez-Girón, A.; Sánchez-Patán, F.; Santos-Buelga, C.; Moreno-Arribas, M.V.; Bartolomé, B. A Survey of Modulation of Gut Microbiota by Dietary Polyphenols. Biomed. Res. Int. 2015, 2015, 1-15. [CrossRef]

68. Viveros, A.; Chamorro, S.; Pizarro, M.; Arija, I.; Centeno, C.; Brenes, A. Effects of dietary polyphenol-rich grape products on intestinal microflora and gut morphology in broiler chicks. Poult. Sci. 2011, 90, 566-578. [CrossRef]

69. Valeriano, V.D.V.; Balolong, M.P.; Kang, D.-K. Probiotic roles of Lactobacillus sp. in swine: Insights from gut microbiota. J. Appl. Microbiol. 2017, 122, 554-567. [CrossRef]

70. Nakphaichit, M.; Thanomwongwattana, S.; Phraephaisarn, C.; Sakamoto, N.; Keawsompong, S.; Nakayama, J.; Nitisinprasert, $\mathrm{S}$. The effect of including Lactobacillus reuteri KUB-AC5 during post-hatch feeding on the growth and ileum microbiota of broiler chickens. Poult. Sci. 2011, 90, 2753-2765. [CrossRef] 
71. O'Callaghan, A.; van Sinderen, D. Bifidobacteria and Their Role as Members of the Human Gut Microbiota. Front. Microbiol. 2016, 7. [CrossRef]

72. Christiaen, S.E.A.; O'Connell Motherway, M.; Bottacini, F.; Lanigan, N.; Casey, P.G.; Huys, G.; Nelis, H.J.; van Sinderen, D.; Coenye, T. Autoinducer-2 plays a crucial role in gut colonization and probiotic functionality of Bifidobacterium breve UCC2003. PLoS ONE 2014, 9, e98111. [CrossRef] [PubMed]

73. LeBlanc, J.G.; Milani, C.; de Giori, G.S.; Sesma, F.; van Sinderen, D.; Ventura, M. Bacteria as vitamin suppliers to their host: A gut microbiota perspective. Curr. Opin. Biotechnol. 2013, 24, 160-168. [CrossRef] [PubMed]

74. Lomax, A.R.; Calder, P.C. Probiotics, immune function, infection and inflammation: A review of the evidence from studies conducted in humans. Curr. Pharm. Des. 2009, 15, 1428-1518. [CrossRef] [PubMed]

75. Venturi, A.; Gionchetti, P.; Rizzello, F.; Johansson, R.; Zucconi, E.; Brigidi, P.; Matteuzzi, D.; Campieri, M. Impact on the composition of the faecal flora by a new probiotic preparation: Preliminary data on maintenance treatment of patients with ulcerative colitis. Aliment. Pharmacol. Ther. 1999, 13, 1103-1108. [CrossRef]

76. Bustos, I.; García-Cayuela, T.; Hernández-Ledesma, B.; Peláez, C.; Requena, T.; Martínez-Cuesta, M.C. Effect of flavan-3-ols on the adhesion of potential probiotic lactobacilli to intestinal cells. J. Agric. Food Chem. 2012, 60, 9082-9088. [CrossRef]

77. Sugimoto, K.; Ogawa, A.; Mizoguchi, E.; Shimomura, Y.; Andoh, A.; Bhan, A.K.; Blumberg, R.S.; Xavier, R.J.; Mizoguchi, A. IL-22 ameliorates intestinal inflammation in a mouse model of ulcerative colitis. J. Clin. Investig. 2008, 118, 534-544. [CrossRef]

78. Shan, M.; Gentile, M.; Yeiser, J.R.; Walland, A.C.; Bornstein, V.U.; Chen, K.; He, B.; Cassis, L.; Bigas, A.; Cols, M.; et al. Mucus Enhances Gut Homeostasis and Oral Tolerance by Delivering Immunoregulatory Signals. Science 2013, 342, 447-453. [CrossRef]

79. Yang, G.; Xue, Y.; Zhang, H.; Du, M.; Zhu, M.-J. Favourable effects of grape seed extract on intestinal epithelial differentiation and barrier function in IL10-deficient mice. Br. J. Nutr. 2015, 114, 15-23. [CrossRef]

80. Al-Sadi, R.M.; Ma, T.Y. IL-1beta causes an increase in intestinal epithelial tight junction permeability. J. Immunol. 2007, 178, 4641-4649. [CrossRef]

81. Mudter, J.; Neurath, M.F. Il-6 signaling in inflammatory bowel disease: Pathophysiological role and clinical relevance. Inflamm. Bowel. Dis. 2007, 13, 1016-1023. [CrossRef]

82. Fridman, J.S.; Lowe, S.W. Control of apoptosis by p53. Oncogene 2003, 22, 9030-9040. [CrossRef] [PubMed]

83. Barbe, A.; Mellouk, N.; Ramé, C.; Grandhaye, J.; Anger, K.; Chahnamian, M.; Ganier, P.; Brionne, A.; Riva, A.; Froment, P.; et al. A grape seed extract maternal dietary supplementation improves egg quality and reduces ovarian steroidogenesis without affecting fertility parameters in reproductive hens. PLoS ONE 2020, 15, e0233169. [CrossRef] [PubMed]

84. Kara, K.; Şentürk, M.; Guclu, B.K.; Sariözkan, S.; Eren, M. Effect of catechins on fattening performance, meat quality, some antioxidant and blood parameters and fattening costs in Japanese quail (Coturnix coturnix japonica). Br. Poult. Sci. 2016, 57, 522-530. [CrossRef]

85. Hafsa, S.H.A.; Ibrahim, S.A. Effect of dietary polyphenol-rich grape seed on growth performance, antioxidant capacity and ileal microflora in broiler chicks. J. Anim. Physiol. An. N. 2018, 102, 268-275. [CrossRef] [PubMed]

(C) 2020 by the authors. Licensee MDPI, Basel, Switzerland. This article is an open access article distributed under the terms and conditions of the Creative Commons Attribution (CC BY) license (http://creativecommons.org/licenses/by/4.0/). 